\title{
Institutional context: What elements shape how community occupational therapists think about their clients' care?
}

\author{
Annie Carrier OT, BA(psy), LLM, PhD ${ }^{1,2}$ (D) | Andrew Freeman OT, $\mathrm{PhD}^{3,4}$ | \\ Johanne Desrosiers OT, $\mathrm{PhD}^{1}$ | Mélanie Levasseur OT, $\mathrm{PhD}^{1,2}$
}

${ }^{1}$ School of Rehabilitation, Faculty of Medicine and Health Sciences, Université de Sherbrooke, Sherbrooke, Canada

${ }^{2}$ Research Centre on Aging, Centre intégré universitaire de santé et de services sociaux de l'Estrie - Centre hospitalier universitaire de Sherbrooke (CIUSSS de l'Estrie - CHUS), Sherbrooke, Canada

${ }^{3}$ Department of Rehabilitation, Faculty of Medicine, Université Laval, Québec, Canada

${ }^{4}$ Centre de recherche sur les soins et les services de première ligne de l'Université Laval (CRESSPL-UL), CIUSSS de la CapitaleNationale, Québec, Canada

\section{Correspondence}

Annie Carrier, 3001 12e avenue nord, Sherbrooke, Québec, Canada J1H 5N4. Email: Annie.Carrier@USherbrooke.ca

Funding information

Fonds de recherche Québec - Santé, Grant/ Award Number: 26815; Canadian Institutes of Health Research, Grant/Award Number: \#250281 and \#360880

\begin{abstract}
Clinical reasoning (CR) is the cognitive process that therapists use to plan, direct, perform and reflect on client care. Linked to intervention efficiency and quality, $\mathrm{CR}$ is a core competency that occurs within an institutional context (legal, regulatory, administrative and organisational elements). Because this context can shape how community therapists think about their clients' care, its involvement in their CR could have a major impact on the interventions delivered. However, little is known about this involvement. Our study thus aimed to describe the elements of the institutional context involved in community therapists' CR. From March 2012 to June 2014, we conducted an institutional ethnography (IE) inquiry in three Health and Social Services Centres in Québec (Canada). We observed participants and conducted semi-structured interviews with 10 occupational therapists. We also interviewed 12 secondary key informants (colleagues and managers) and collected administrative documents $(n=50)$. We analysed data using the IE process. Of the 13 elements of the institutional context identified, we found that four are almost constantly involved in participants' CR. These four elements, that is, institutional procedures, organisation's basket of services, occupational therapists' mandate and wait times for their services, restrictively shape CR. Specifically, occupational therapists restrict their representation of the client's situation and exploration of potential solutions to what is possible within the bounds of these four elements. In light of such restrictions on the way they think about their clients' care, therapists should pay close attention to the elements of their own institutional context and how they are involved in their CR. Because of its potentially important impact on the future of professions (e.g. further restrictions on professionals' role, reduced contribution to population health and well-being), this involvement of the institutional context in CR concerns all professionals, be they clinicians, educators, researchers or regulatory college officers.
\end{abstract}

\section{KEYWORDS}

( ${ }^{*}$ designates MESH terms), decision making, home care services, occupational therapists, problem solving, professional practice, waiting lists 


\section{1 | INTRODUCTION}

Defined as 'the process that practitioners use to plan, direct, perform, and reflect on client care' (Schell, 2009; p. 314), clinical reasoning (CR) is the basis of practice (Schell \& Schell, 2008a) and professional actions (Norman, 2005). Involving problem-solving and decision-making (Lindsay \& Norman, 1977), this complex and context-dependent process has been linked to intervention efficiency and quality (Schell \& Schell, 2008b).

According to various theoretical models (e.g. Contandriopoulos, Rey, Brousselle, \& Champagne, 2012; Craik, Davis, \& Polatajko, 2013; Pfadenhauer et al., 2017), health and social interventions occur within and are influenced by contexts, that is, practice setting (practice context) and society (societal context). These contexts are intertwined and multidimensional, and include cultural, social, physical and institutional dimensions (Craik et al., 2013). Among these four dimensions, the institutional (Table 1) exerts an implicit and diffuse influence on professionals' choice of intervention (Carrier, Levasseur, Bédard, \& Desrosiers, 2012), which is different from (Davidoff, 2019) and greater than that exerted by the personal context (Barris, 1987), that is, therapist's individual characteristics (e.g. values and perceived self-efficacy; Carrier, Levasseur, Bédard, \& Desrosiers, 2010). More broadly, the institutional dimension is a lever frequently used by decision-makers to optimise healthcare (Powell, Davies, Bannister, \& Macrae, 2009) through legislative and regulatory reforms (legal and regulatory elements), new policies (administrative elements), and service delivery and financing modalities (organisational elements). Although the institutional dimension is a source of organisational power (Poland, Lehoux, Holmes, $\&$ Andrews, 2005), professionals can also modulate it to influence practice (Cooper, 2012).

In recent years, the institutional dimension has evolved (Mackey, 2014), notably in the community (homecare) setting (Demers \& Pelchat, 2012/2013), which has become a major priority for healthcare systems worldwide (Lamarche, Pineault, \& Brunelle, 2007). In Québec (Canada), resource allocation to homecare programmes has expanded rapidly, and this trend is likely to continue (Hébert, 2012). Importantly, this allocation has recently been coupled with productivity targets (Act respecting Health Services \& Social Services, s. $182.1 \mathrm{ff}$.), that is, specific annual intervention volume associated with each type of client and professional. In addition to productivity targets, therapists must satisfy increased professional obligations, such as changes in shared protected acts or new professional competencies. Considering productivity targets and professional obligations, professionals may experience ethical tensions that affect their CR (Freeman, McWilliam, MacKinnon, DeLuca, \& Rappolt, 2009).

Despite the potential influence of a constantly changing (Mackey, 2014) and increasingly complex healthcare context (Sturmberg, O'Halloran, \& Martin, 2012), the precise involvement of healthcare's institutional dimension in CR has not been studied (Schell, Unsworth, \& Schell, 2008). Although some evidence indicates that this dimension affects elements closely

\section{What is known about this topic}

- Through laws, regulations, policies and service organisation, decision-makers use the institutional context as a lever to optimise community healthcare.

- The institutional context exerts an implicit and diffuse influence on professionals' choice of intervention and other elements closely linked to their CR.

- $\mathrm{CR}$ is the basis of practice and professional actions and, therefore, affects the quality and relevance of care.

\section{What this paper adds}

- Institutional elements are involved throughout community therapists' $C R$.

- Administrative and organisational elements are constantly considered in CR, whereas legal and regulatory elements are less involved.

- Through their involvement in problem-solving, four elements, that is, procedures, basket of services, mandate and wait times, affect the scope of both services offered and professional practice.

linked to CR, such as the desire for productivity (Rudge, 2013) and clinical and administrative actions (Comtois, Paris, Poder, \& Chaussé, 2013), little is known about the explicit links between this dimension and CR. It is essential to understand how external forces shape professionals' cognitive reasoning, courses of action considered (Davidoff, 2019) and practice (Cooper, 2012) because of serious potential impacts on patients. Externally shaped professional practice can lead to discrimination, social exclusion and marginalisation, social and health inequities (Poland et al., 2005), and occupational injustice (Durocher, Rappolt, \& Gibson, 2013). Furthermore, knowing more about contextual elements and their involvement may help tailor more effective quality improvement efforts that will increase the relevance of care (Davidoff, 2019). This study thus aimed to describe elements of the institutional dimension and their involvement in the CR of community occupational therapists throughout their practice.

\section{2 | METHODS}

\section{1 | Design}

This study was part of a larger study exploring how community occupational therapists activate measurement and accountability in their everyday practice. We used a qualitative institutional ethnography (IE) research design from a constructivist perspective, starting from the actual work of people (Campbell \& Gregor, 2002), here, community occupational therapists. We chose IE because, based on the 
Social Theory of Knowledge (Campbell, 2006; Campbell \& Gregor, 2002; Smith, 1987, 2005), it aims to determine how peoples' everyday work (here, practice) is shaped by external forces through the use of documents. This requires a two-phase approach (Campbell \& Gregor, 2002).

First, we had to describe what occupational therapists do, cognitively (CR) and physically. The entry point of an IE study is the standpoint of key informants, here, occupational therapists. Taking their standpoint and describing their work were made easier because the first author practiced as a community occupational therapist for 10 years, which increased our sensitivity to their everyday lives (Campbell \& Gregor, 2002; Smith, 2006). From their standpoint and work description, we identified institutional elements involved in their CR. We operationalised CR as what participants described when asked what they were thinking while doing their job. Findings from the first phase, that is, description of community occupational therapists' CR, institutional elements involved in their $\mathrm{CR}$ and how they are involved are the subject of this paper.

Second, to meet the objectives of the larger study, we explicated how the actions described (CR) were coordinated using a variety of analytical strategies. These detailed methods (Carrier, Freeman, Levasseur, \& Desrosiers, 2014) and results from the larger study (Carrier, Freeman, Levasseur, \& Desrosiers, 2015; Carrier, Levasseur, Freeman, \& Desrosiers, 2016) have been published elsewhere and

\section{TABLE 1 Definition of key concepts}

\begin{tabular}{|c|c|}
\hline Concept & Definition \\
\hline Context & $\begin{array}{l}\text { The practice context is the level at which professional } \\
\text { and client interact (e.g. clinical setting). } \\
\text { The societal context is the overall level of healthcare } \\
\text { organisation (e.g. government, provincial health and } \\
\text { social services department). Practice and societal } \\
\text { contexts are multidimensional environments within } \\
\text { which professionals' interventions take place. These } \\
\text { dimensions can be physical, social, cultural and } \\
\text { institutional. }\end{array}$ \\
\hline
\end{tabular}

Institutional 'Structures that promote social order and govern dimension society' overall and locally, economically, politically and legally (Polatajko et al., 2013, p. 52). Here, 'structures' or 'institution' does not refer to a specific organisation; rather, it is a complex of social relations which are textually mediated and replicated across multiple local sites and times (Smith, 2001).

The institutional dimension includes legal, regulatory, administrative and organisational elements.

Institutional Legal: Relating to legislation, jurisprudence and elements contracts.

Regulatory: Relating to regulations adopted in accordance with enabling legislation.

Administrative: Relating to healthcare policies and guidelines.

Organisational: Relating to the organisation of work and services, such as schedules, waiting lists, caseloads, etc.

Adapted from Carrier, et al. (2014). will not be discussed here. Ethical approval was obtained from the Research Ethics Committee of the healthcare organisation involved [MP-CSSS-ESTRIE-11-11/AUTHOR]. All participants gave their free, informed, written consent.

\section{2 | Participants and data collection}

Managers of four of seven home-care programmes in the province of Québec agreed to participate in the study. Using purposeful sampling, we selected three settings with different numbers of occupational therapists and locations (urban and rural). We wanted to increase contextual heterogeneity to capture the essence of the external forces involved. By email and telephone, we contacted the 17 community occupational therapists working as clinicians in these home-care programmes and 10 agreed to participate in the study. Although convenient, this sampling technique produced a variety of participant characteristics (e.g. years of experience, gender, programme of affiliation).

In the first two home-care programmes, we observed occupational therapists' work during home visits and at the office ( $n=39$ days). We conducted 206 on-the-spot informal interviews (totalling $16 \mathrm{hr} 29 \mathrm{~min}$ ) and seven formal interviews (8 hr $4 \mathrm{~min}$ ). Interviews were recorded and transcribed. The aim was to document participants' CR underlying observed actions requiring a document (e.g. referral form) or indicative of the possible involvement of the institutional dimension (e.g. reference to an administrative guideline; Smith, 2001). We asked questions such as What leads you to do [x action]?; What other elements guide you in doing [x action]?

The occupational therapists contacted 12 secondary informants (colleagues and managers) from programmes 1 and 2 whom they identified as having relevant information about institutional elements; they all agreed to participate. We interviewed them informally (on-the-spot; $n=18$ ) and formally $(n=4)$. We also conducted formal interviews with participants from the third home-care programme ( $n=3 ; 4$ hr 2 min). Informal and formal interviews were recorded and transcribed. We retrieved all organisational documents $(n=50)$ used (observations) or referred to (interviews). All community occupational therapists completed a self-administered sociodemographic questionnaire. We collected data on programme 1 in March 2012, programme 2 from May 2012 to March 2013 and programme 3 from April to June 2014. Using Word@, we transcribed observation logs and integrated them in chronological order with transcripts from onthe-spot interviews with occupational therapists (actions observed, underlying $(\mathrm{R})$ and documents involved.

\section{3 | Data analysis}

During and between each data collection period, the first author analysed the data using the IE first phase analysis process (Campbell \& Gregor, 2002). Specifically, we grouped participants' 
similar actions from integrated observations and on-the-spot interviews into sequences of actions (e.g. work involving the referral form) and labelled them using their own words (e.g. treating the referral). We used a logbook to develop links between sequences, leading to a description of stages in the practice process (e.g. Stage 1: From treating the referral to accepting the client). To support linkage development, we also used mapping (Campbell \& Gregor, 2002; Turner, 2006) and questions such as What cognitive actions does this occupational therapist explicitly or implicitly describe? How are these actions connected to those of other occupational therapists? What institutional elements (as defined in Table 1) does this key informant describe? How is $C R$ related to these elements? (McCoy, 2006). Through data integration, mapping and questions, we identified institutional elements and their involvement in CR across the practice process. The logbook guided subsequent data collection through changes to the informal interview guide, customising formal interview guides and selecting key informants (Campbell \& Gregor, 2002). We developed the description of institutional elements using data from interviews (all informants) and, when relevant, documents. As suggested by Campbell and Gregor (2002), we discussed analyses extensively within the research team.

\section{3 | FINDINGS}

\section{1 | Participants}

The occupational therapist participants included eight women and two men; the majority had more than 5 years of experience in community services $(n=7)$ and worked together in one urban setting $(n=6)$. The others were members of small rural teams of two or three community occupational therapists. Four participants worked in various home-care department programmes, while six were involved in one or two specific programmes (short-term services, palliative care, mental health, evaluation team, support for older adults, physical disability, mobility programmes assessment). Secondary informants included one case manager, two physical therapists, two clinical supervisors, two mid-level and one highlevel managers, two technical support staff and two other occupational therapists.

\section{2 | Involvement of institutional dimension in clinical reasoning across practice process}

We identified three practice process stages: (a) From treating the referral to accepting the client; (b) From assessing to intervening and (c) From following up to closing the file. In the CR underlying these stages, participants considered three legal, two regulatory, four administrative and four organisational elements. Integrating data from interviews and documents, we describe these 13 institutional elements in Table 2. We found that administrative and organisational elements are more frequently involved than legal and regulatory elements. Below, we describe the almost constant involvement of four elements in participants' CR across their practice process; two are administrative $(A)$ : institutional procedures and organisation's service offer (basket), and two are organisational (O): occupational therapists' mandate and wait times for services. We also show how these elements restrictively shape the way community occupational therapists think about their clients' care.

\section{3 | Stage 1: From treating the referral to accepting the client}

The first decision occupational therapists make is whether to accept, redirect or refuse a referral. From the referral form, occupational therapists first juggle personal safety and autonomy, the organisation's service offer $(A)$ and the delay in accessing services (O). As illustrated below, an occupational therapist wonders what to do with a referral for hygiene problems following surgery because her organisation no longer offers occupational therapists' assessment of autonomy and safety for these situations:

I was told that I did not respond to [hygiene problems following surgery]. Am I putting my client in danger by refusing to go [to her home]? It's all very well having administrative rules. What makes me circumvent them is the length of [wait time], it's [the person's] safety.

(OT2)

This juggling also involves referral procedures $(A)$ and service offers from other partners (e.g. rehabilitation centre, community organisations; A). For example, this participant wonders if he should accept the referral, given the lack of occupational therapy services from a partner organisation:

There have already been disagreements [with] the [mental rehabilitation center], they don't have an occupational therapist. Each time there's a user who needs one: Is it or isn't it us?

When other team members are involved, occupational therapists consider their mandate (e.g. short-term vs. palliative care; O), their teammates' mandates (O; Table 2 ) and the reason for referral. For example, if the reason is a shared activity (e.g. mobility) in which their involvement does not appear to add value, the referral will not be accepted, as illustrated here: 'As long as the physio goes there, he can make arrangements for a transfer bench' (OT8).

If determined to be eligible, occupational therapists prioritise the referral using a priority grid; to do so, they consider the reason for referral, organisation's service offer (A) and institutional procedures (A). The priority grid helps participants determine the urgency of the 
TABLE 2 Description of institutional dimension elements involved in community occupational therapists' clinical reasoning throughout the practice process

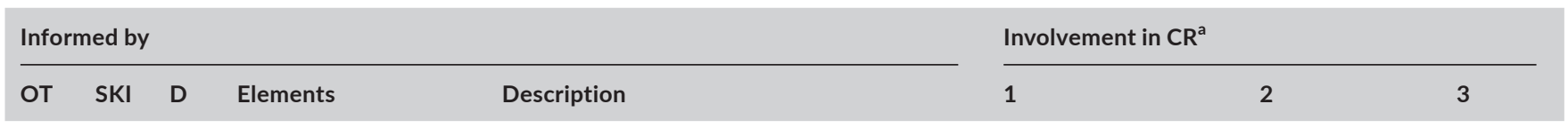

LEGAL elements: clauses from various laws

\begin{tabular}{|c|c|c|c|}
\hline & & Clauses regarding & \\
\hline • & $\bullet$ & - Clients' rights & $\begin{array}{l}\text { Rights of health and social system users as } \\
\text { defined in the LSSSS and the CcQ }\end{array}$ \\
\hline & $\bullet$ & $\begin{array}{l}\text { - Organisations' } \\
\text { missions }\end{array}$ & $\begin{array}{l}\text { Role of each organisation as defined in the } \\
\text { LSSSS, including type of services to offer }\end{array}$ \\
\hline & & $\begin{array}{l}\text { - Occupational } \\
\text { health and safety }\end{array}$ & $\begin{array}{l}\text { Occupational health and safety protection } \\
\text { rights of employees as defined in the LSST }\end{array}$ \\
\hline
\end{tabular}

REGULATORY elements: regulations (inside and outside the professional regulatory body)

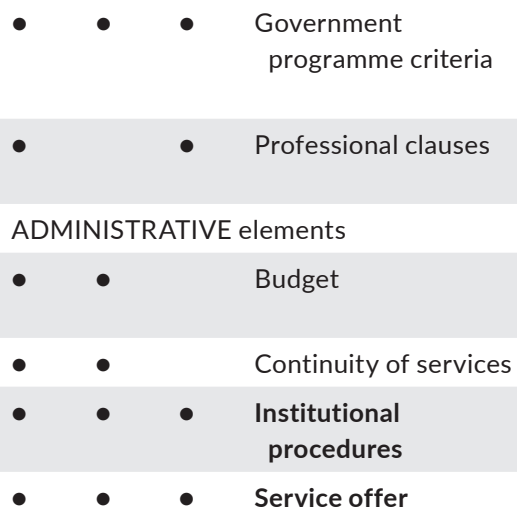

ORGANISATIONAL elements Availability of
colleagues

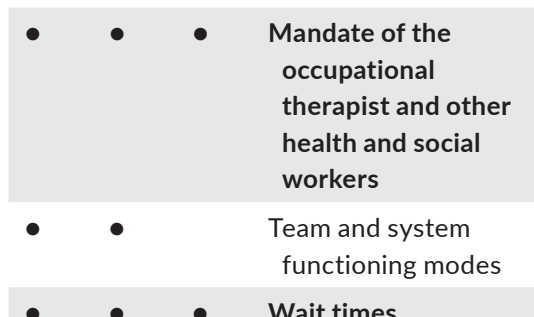

- $\quad$ Wait times

Conditions to meet for funding (money or equipment and assistive devices), according to each programme

Code of ethics and regulations for file reporting

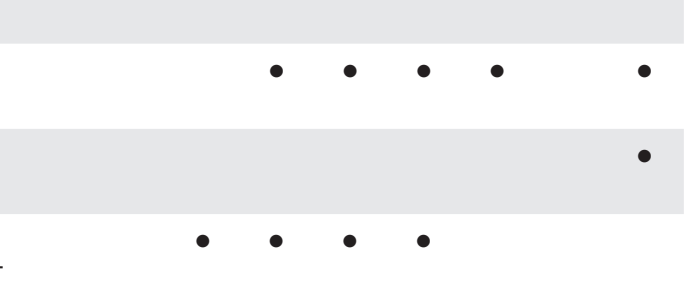

(1)

(1)

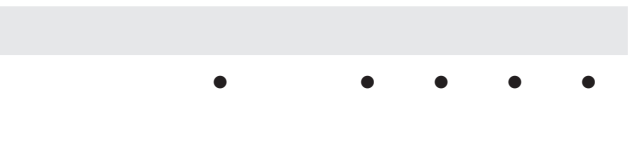

(a)
Cost of an intervention linked to the home- care organisation's financial resources
Care pathways for a given client
Home-care organisation or healthcare system rules to follow in a given situation
Services offered by the organisation and partners

\section{Ability or inability to appeal to other health and social workers due to their absence (e.g. annual vacation)}

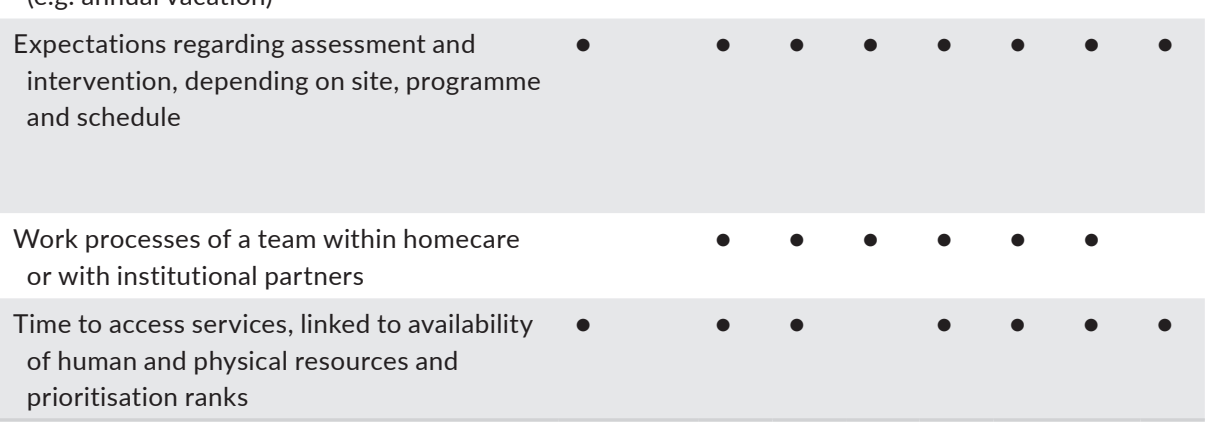

anvolvement of each institutional element in participants' CR was determined for each sequence of actions that were part of the practice process stage: (1) From treating the referral to accepting the client (three sequences of actions), (2) From assessing to intervening (three sequences of actions) and (3) From following up to closing the file (two sequences of actions). If a dot is present, it means the institutional element was considered by the participants in that sequence of actions. If the element is bolded, it means it was involved in more than $87.5 \%$ of community occupational therapists' CR; CcQ: Code civil du Québec/ Civil Code of Québec; LSSSS: Loi sur les services de santé et les services sociaux/ Act respecting Health Services and Social Services; LSST: Loi sur la santé et la sécurité au travail/ Act respecting Occupational Health and Safety; OT: occupational therapist participants; SKI: secondary key informants; D: documents.

referral and recommended take-over time: Priority 1 is unavoidable risk (e.g. fire hazard)-within 48 hr; Priority 2 is imminent risk (e.g. risk of developing a sore)-within a week; Priority 3 is probable risk (e.g. possible caregiver burnout)-whenever possible; and Priority 4 is optional or preventive services-whenever possible.
Before accepting a new client, occupational therapists consider their workload and the priority level referrals on the waiting list (O) associated with their mandate (O). On the one hand, institutional procedures ( $\mathrm{A}$; Table 2 ) might delay the acceptance of higher priority cases, as shown here: 
A [priority 2 request] in a private home dealing with insect pests. The institution has issued a directive that there will be no home visits for a month. [stays on the waiting list]

(Observation OT6)

On the other hand, time available $(\mathrm{O})$ might accelerate the acceptance of lower priority cases, as follows:

Tells me she's going to schedule a 'quickie' - a lower priority case usually going under the pile. This one, she'll take anyhow because she wants to do a home visit this afternoon.

(Observation OT6)

Once accepted, and using mostly the information on the referral form, community occupational therapists start to create their mental representation of the client's occupational situation. This enables them to visualise possible solutions and courses of action and anticipate assessment and intervention.

\section{4 | Stage 2: From assessing to intervening}

Although community occupational therapists typically assess and intervene at their clients' homes, they might also do assessments at the office. They choose this option to avoid home visits outside their regular work hours (mandate [O]; Table 2) when their presence does not add value: 'It's not during my work hours at all, it really has to be clear that it's required and that I cannot do it any other way' (OT3). Occupational therapists then choose to evaluate the client through team members (e.g. home-care workers): 'It's an indirect [assessment]. We rely on what our colleagues say. If they all tell me the same thing, I don't have any reason to think I'll see something else by going there' (OT3).

When assessing and intervening at clients' homes, occupational therapists consider their organisation's service offer as well as that of partners (A). This leads them to question what they should do in terms of assessment. The next excerpt illustrates an occupational therapist wondering if she is restricting the scope of her evaluation too much because of her organisation's basket of services:

Should I do more? Really dig for all the needs, even if they aren't mentioned by the case manager? Look at leisure activities, occupation? I never did that since we are restricted because we're a [homecare program]. It was decided that we just do ADL and IADL. We focus more on 'Is staying at home compromised or not?' I never got into the leisure aspect but should I? That's what I wonder about, about occupation in general, the whole person.

To avoid duplication, occupational therapists' scope of investigation is also influenced by their mandate (O; Table 2 ) and that of their team members (O). Depending on the programme (e.g. short-term services, mental health), the mandate may be consulting with the team
Occupational therapists are then not supposed to intervene over the long term, as illustrated here:

I'm a consultant. I get requests from my colleagues, who have already done the [standardized institutional] assessment, and I respond to the request, I stabilize the situation, do my short-term interventions and close the file.

(OT6)

When choosing their intervention plan, occupational therapists consider the same elements as during the assessment, such as their limited mandate (O). Here, coming back from a home visit where several complex needs were unearthed and a long-term follow-up appeared necessary, the occupational therapist repeats several times: 'My hands are tied, we're wasting time' (Observation OT2). When asked what she meant by 'My hands are tied', the participant replied: 'My hands are tied because I'm supposed to do short-term things. Short-term means I go in and get out [of the home]' (OT2). The mandate of other professionals $(\mathrm{O})$ also influences their choice of intervention plan. For example, when a physical therapist is involved, occupational therapists typically adjust their intervention: 'I'I try not to duplicate what [the physical therapist] has done' (OT3). However, the therapists juggle multiple other elements: institutional procedures (e.g. for loaning equipment; A), organisation's service offer (A) as it relates to the client's specific programme (e.g. electric bed can be loaned for palliative but not shortterm care) and expected delay in accessing those services (O).

A significant number of community occupational therapy interventions take place without the client being present, in the office or elsewhere, and the institutional elements involved depend on the nature of the interventions. For example, adapting an assistive device requires knowledge of institutional procedures $(A)$ regarding possible assistance from technical support staff.

\subsection{Stage 3: From following up to closing the file}

When following up with clients, community occupational therapists' $\mathrm{CR}$ is very similar to that when accepting a client. They actively search for information, shaping their representation of their clients' occupational situation, which, in turn, organises their subsequent actions. This search for and transmission of information to the appropriate individuals is modulated by other team members' availability and mandates (O). Here, the occupational therapist wants to share important information but must consider the impossibility of scheduling a team meeting rapidly: '[The pivot social worker] coordinates; she told me a [meeting] was scheduled in two weeks. It's impossible to get them quickly' (OT6).

Occupational therapists decide to close a file for a variety of reasons: change in the client's situation (e.g. move to residential care), successful intervention, objectives impossible to achieve, limitations in the occupational therapist's mandate (sometimes relative to the mandate of other professionals; O) and institutional procedure for closing files (A). According to this procedure, the file should be 
closed as soon as the referral is completed: '[Clinical coordinator] says: No, no, they have to be closed. The request is completed, you close your request. If there's another request, they'll do [it]. Because otherwise our files stay open' (OT4).

How this institutional procedure is involved in occupational therapists' decision to close the file is illustrated here:

For that client, steps are underway to assign a walker and, on the recommendation of my immediate superior, I decided to close the file, although the intervention is ongoing because we are at the stage of getting a prescription [which] can be very laborious, very long, because it's a prescription from a specialist. For the few months or perhaps a year that it could take... In these cases, we decided to close the file and have a new request when the file is about to be completed.

When discharge is sudden (change in the situation), administrative termination is decided immediately. In other instances, community occupational therapists choose to suspend follow-up without administrative termination. This is the option when, for example, there is a chance that the client might return home after hospitalisation, as illustrated here:

My intervention is not really [participant hesitates], it's not finished, it's in abeyance. Because he is hospitalized and his wife won't take him back. But it's a psychological conjugal violence situation. If she [weakens] and ends up saying: 'I'll take him back', we'll restart the process. It's less complicated if I don't close it.

The occupational therapist might also delay administrative termination for a few weeks when the client's situation is complex, as here:

There are some files where it's always more complicated but leaving them open all the time for that reason, no. My interventions are done, one or two weeks, I warn them, and if there are no other needs, I close the file, I don't leave it open just in case, sometimes.

Such decisions (suspension and delay) are the solution occupational therapists use to prevent pop-ups. Pop-ups are immediate new requests from clients whose files have been prematurely closed because of institutional procedures. These suspended and delayed files are considered inactive and reviewed by a superior: 'Told me that a superior had called to ask why an inactive request was in her caseload. [...] it's not an oversight, it's a file where there could be a pop-up' (Observation OT6). These decisions to suspend or delay administrative termination are motivated by the desire to reduce paperwork: 'There are some specific contexts in which I will leave the file open [...] they come up again every two or three months, and it's tiresome to keep closing and opening the file. [...] it's work for nothing' (OT8). These decisions also allow a client to keep the same occupational therapist in the event of a pop-up.

\section{4 | DISCUSSION}

The CR of community occupational therapists involves legal, regulatory, administrative and organisational elements. Institutional procedures and service offer (administrative elements), mandate and wait times (organisational elements) are the four most common. Providing substantial empirical confirmation for the theory that contexts are important, these findings document for the first time the involvement of the institutional dimension in the CR of one group of Québec community occupational therapists.

The findings also provide support for Carrier et al. (2012) contention that the practice context exerts an implicit and diffuse influence on community occupational therapists' CR. The present study indicates precisely which elements of the context are involved and how they are involved. Institutional elements appear to be involved in the problem-solving process (representation of the situation and potential solutions) and also modulate the decision-making process (evaluation and choice of solutions). This study did not seek to determine whether the influence of the practice context is greater than that of the therapists' personal context, as suggested by Barris (1987), or if the personal context mitigates the institutional dimension's influence on CR. However, it did reveal that some administrative (procedures and service offer) and organisational (occupational therapists' mandate and wait times) elements were pervasively and frequently involved.

Our results show that the way community occupational therapists think about their clients' care is particularly shaped by four institutional elements, namely long wait times, limited mandate, restrictive institutional procedures and basket of services. Throughout the practice process, occupational therapists decide whether and how to intervene according not to their clients' needs but to existing institutional imperatives. Even more alarming, participants consider these institutional imperatives while forming their mental representation of the client's situation (problem-solving phase of CR), and not just when evaluating and choosing possible solutions (decision-making phase of $\mathrm{CR}$ ). Thus, potentially appropriate interventions might not be considered, not because they are inadequate or unavailable (evaluation and choice of solutions), but because they are not even considered to begin with. This scenario is important for two reasons.

First, it could significantly reduce the range of interventions offered to clients to meet their needs and thus impact their choice, restricting their legal right to community healthcare (Carrier, Levasseur, \& Mullins, 2010). If they are not even informed about possible appropriate interventions because professionals never consider them in their $\mathrm{CR}$, clients and their caregivers are deprived of their power: they cannot even advocate for the appropriate services and remain with unmet needs. In a community context, unmet needs can lead to hospitalisations, residential care or increased burden on caregivers (Tousignant, Dubuc, Hébert, \& Coulombe, 2007), all of which run counter to the 
ageing-in-place movement. Through their unseen and pervasive effects on $C R$ and professional practice, institutional imperatives can also result in discrimination, social exclusion, health inequities (Poland et al., 2005) and occupational injustice (Durocher et al., 2013).

Second, this scenario might progressively and insidiously restrict the scope of community occupational therapy services in Québec (Carrier, Levasseur, \& Mullins, 2010; Hébert, Maheux, \& Potvin, 2002), as has been noted in community social work (e.g. Benoit \& Perron, 2019) and community practice across the globe (e.g. Rostgaard, 2012; Vabø, 2012). Such a limitation raises questions regarding service quality (Carrier, Levasseur, \& Mullins, 2010) and the relevance of care (Davidoff, 2019) for community occupational therapists and other professionals. The normative dimension of quality is determined by compliance with professional standards of practice (Donabedian, 1980). These standards are the basis of professional systems: they act as a public safeguard and foster the relevance of care. Given current financial challenges facing healthcare systems worldwide (WHO, 2010), safety and relevance are explicitly identified as key objectives (Commissaire à la santé et au bien-être, 2016). Over the long term, a significant restriction on the scope of practice could lead to practices that no longer meet professional standards, directly impacting the quality and relevance of services and jeopardising the financial sustainability of health systems.

Since institutional elements are frequently involved in professionals' CR, the basis of practice (Schell \& Schell, 2008a; 2008b), this also raises questions about the future and autonomy of professions and the actual power of their regulatory colleges/associations in shaping their practice. Professional practice is supposed to be determined by professionals themselves, through professional laws and regulations implemented by regulatory colleges and associations. However, legal and regulatory elements were rarely involved in our participants' CR. These elements may need to be supported by coherent administrative and organisational elements aligned with professional evidence-based practice and values, such as client-centeredness (see Implications for Practice). Considering current efforts to optimise healthcare and associated measurement and accountability requirements in Québec (Ministère de la Santé et des Services sociaux, 2017; LSSSS, s. 182.1 ff.) and elsewhere (Gray, Berta, Deber, \& Lum, 2014; Oomkens, Hoogenboom, \& Knijin, 2016; Rostgaard, 2012; Vabø, 2012), professional regulatory colleges/associations should be aware of potential threats to the public interest and the quality of professional services, and also consider how best to support therapists in their everyday work.

\section{1 | Implications for practice}

Institutional elements that shape and are shaped by practice need to be more explicitly and systematically considered by community therapists (Cooper, 2012; Townsend, Polatajko, Craik, \& Zweck, 2011). To do this, we suggest two possible courses of action. First, clinicians and students need to make explicit institutional elements that often implicitly influence their CR. Through this explicit awareness, levers of action can be identified to reduce negative influences on responses to clients' needs. To unearth implicit influences, clinicians and students can utilise reflexive practice and reflective tools (e.g. Carrier, Levasseur, Bédard, \& Desrosiers, 2015; Carrier \& Prodinger, 2014). Educators, fieldwork supervisors and academics also play a vital role in incorporating institutional elements more explicitly in their teaching and sharing existing tools to foster explicitation. Second, more research is needed to enhance understanding of how contexts affect practice. Through the second-level analysis of the present IE inquiry, we explored how community occupational therapists activate measurement and accountability in their work. Our results detail how standardisation (Carrier, Levasseur, et al., 2015) and performance optimisation (Carrier et al., 2016) shape and limit the scope of professional practice and hence the response to clients' needs. Knowing more about these elements might help professional regulatory colleges/associations advocate for performance indicators that sustain rather than conflict with professional values (Townsend et al., 2011). For example, health indicators adapted to the varying characteristics of healthcare organisations (Smith, 2010) could be coherent with individuals' experience of health and supportive of client-centred healthcare (Sturmberg et al., 2012).

\section{2 | Strengths and limitations}

Our study adds to prior studies on therapists' CR: it examines the specific involvement of institutional elements in CR. We made methodological choices that increased scientific rigor and produced rich data through in-depth interviews and prolonged exposure in the field (Campbell \& Gregor, 2002). The first author's professional experience in community occupational therapy increased sensitivity to the participants' perspective and gave us a deeper understanding of community occupational therapists' everyday work and how, through documents, the institutional context shapes their actions. However, our preconceptions might have influenced our findings. For example, we believe that professional autonomy should be completely protected. We mitigated this risk by the use of memos, triangulation of researchers, and discussions with IE methodological experts and organisational management researchers. The first author knew some of the participants, which might have negatively impacted data collection (participants' self-censorship, researchers' observations biased). However, since this acquaintance also meant that we were able to recruit participants easily and develop a trusting relationship with each person, it might also have been a positive influence (greater trust, richer data).

\section{5 | CONCLUSION}

Our study describes elements of the institutional dimension involved in community occupational therapists' CR and how they are involved. Legal, regulatory, administrative and organisational elements of this dimension shaped the therapists' problem-solving (representation of the situation and potential solutions) and decision-making 
(evaluation and choice of solutions) processes. Administrative (institutional procedures and service offer) and organisational (mandate and wait times) elements are pervasively and more frequently present. They limit the scope of interventions and thus the scope of practice.

Our findings suggest that clinicians should pay attention to the institutional dimension of their contexts and its potential for facilitating or constraining the types of interventions offered to clients. Similarly, students would benefit from curricula that examine the institutional elements of contexts more explicitly. The significant involvement of these institutional elements in therapists' $C R$, the basis of practice, could have an important effect on the future of professions. Possible impacts might include further restrictions on community therapists' roles and, consequently, reduced contribution to population health and well-being. Therefore, involvement of the institutional dimension in CR concerns all professionals, be they clinicians, educators, researchers or regulatory college officers. Ensuring the capacity to offer quality client-centred services, consistent with professional values and the change agent role, requires concerted and continuous efforts by stakeholders on various fronts. These include the clinical setting (e.g. clinicians and managers advocating for institutional elements supporting quality client-centred care), professional associations (e.g. informing politicians about impacts of institutional elements), professional regulatory colleges (e.g. drawing attention to restrictions on members' ability to fulfil their professional obligations) and academics (e.g. submitting proposals to government commissions and using traditional and social media).

\section{ACKNOWLEDGEMENT}

Sincere thanks to all the occupational therapists and their colleagues who generously agreed to participate in this study. At the time of the study, Annie Carrier was a Canadian Institutes of Health Research (\#250281) and Canadian Occupational Therapy Foundation scholarship doctoral candidate and Mélanie Levasseur was a Fonds de la recherche du Québec - Santé Junior 1 Researcher (\#26815). Mélanie Levasseur is now a Canadian Institutes of Health Research (CIHR) New Investigator (\#360880).

\section{CONFLICT OF INTEREST}

The authors declare that they have no conflict of interest.

\section{ORCID}

Annie Carrier (iD https://orcid.org/0000-0002-8890-6098

\section{REFERENCES}

Act respecting Health Services and Social Services, L.R.Q., c. S-4.2 (Québec, Canada: Government of Québec). Available from: http:// legisquebec.gouv.qc.ca/fr/showdoc/cs/s-4.2

Barris, R. (1987). Clinical reasoning in psychosocial occupational therapy: The evaluation process. Occupational Therapy Journal of Research, 7 , 147-162.

Benoit, M., \& Perron, L. (2019). Faire plus avec moins : récit du quotidien des travailleuses de première lignedans les services à domicile. [Doing more with less: A story of the daily lives of front-line workers in home care.] Les conférences du Centre de recherche et d'expertise en gérontologiesociale. 15 March 2019, Montréal, Québec.

Campbell, M. (2006). Institutional ethnography and experience as data. In D. E. Smith (Ed.), Institutional ethnography as practice (pp. 91-107). Lanham, MD: Rowman \& Littlefield Publishers Inc.

Campbell, M., \& Gregor, F. (2002). Mapping social relations: A primer in doing institutional ethnography. Aurora, ON: Garamond Press.

Carrier, A., Freeman, A., Levasseur, M., \& Desrosiers, J. (2014). Exploring the involvement of the institutional dimension of societal and practice contexts in community occupational therapists' clinical reasoning: An institutional ethnography study protocol. European Journal for Person Centered Healthcare, 2, 425-433. https://doi. org/10.5750\%2Fejpch.v2i4

Carrier, A., Freeman, A., Levasseur, M., \& Desrosiers, J. (2015). Standardised referral form: Restricting client-centred practice? Scandinavian Journal of Occupational Therapy Special Issue "critical Perspectives on Client-Centred Occupational Therapy", 22(4), 283-292. https://doi.org/10.3109/11038128.2015.1019922

Carrier, A., Levasseur, M., Bédard, D., \& Desrosiers, J. (2010). Community occupational therapists' clinical reasoning: Identifying tacit knowledge. Australian Occupational Therapy Journal, 57, 356-365. https:// doi.org/10.1111/j.1440-1630.2010.00875.x

Carrier, A., Levasseur, M., Bédard, D., \& Desrosiers, J. (2012). Clinical reasoning process underlying choice of teaching strategies: A framework to improve occupational therapists' transfer skill interventions. Australian Occupational Therapy Journal, 59, 355-366. https://doi. org/10.1111/j.1440-1630.2012.01017.x

Carrier, A., Levasseur, M., Bédard, D., \& Desrosiers, J. (2015). Clinical reasoning process: Cornerstone of effective occupational therapy practice. In I. Söderback (Ed.), International Handbook of Occupational Therapy Interventions, 2ndedn. (73-82). Switzerland: Springer. https:// doi.org/10.1007/978-3-319-08141-0_5

Carrier, A., Levasseur, M., Freeman, A., \& Desrosiers, J. (2016). Reddition de compte et optimisation de la performance dans les Centres de santé et de services sociaux québécois: Impacts sur le choix des interventions des ergothérapeutes [Accountability and performance optimization in Health and Social Services Centres in Québec: Influence on occupational therapists' choice of interventions]. Revue De Santé Publique, 28(6), 769-780.

Carrier, A., Levasseur, M., \& Mullins, G. (2010). Accessibility of occupational therapy community services: A legal, ethical and clinical analysis. Occupational Therapy in Health Care, 24, 360-376. https://doi. org/10.3109/07380577.2010.510170

Carrier, A., \& Prodinger, B. (2014). Visions of possibility: Using Institutional ethnography as a theory and method for understanding contexts and their ruling relations. OT Now Special Issue "Visions of possibility: Creative occupational solutions for today's occupational challenges", 16.2, 18-21.

Commissaire à la santé et au bien-être. (2016). Entendre la voix citoyenne pour améliorer l'offre de soinset services. Rapport d'appréciation thématique de la performance du système de santé et de services sociaux 2016 - Un état des lieux. Addenda II - Pertinence des soins et des services. [Hearing the citizen's voice to improve the provision of care and services.Thematic evaluation report on the performance of the health and social services system 2016 - An overview. Addendum II - Relevance of Care and Services.] Québec, QC: Author.

Comtois, J., Paris, Y., Poder, T. G., \& Chaussé, S. (2013). L'approche Kaizen au Centre hospitalier universitaire de Sherbrooke (CHUS): Un avantage organisationnel significatif [The Kaizen approach at the Sherbrooke University Hospital: A significant organizational advantage]. Santé Publique, 25, 169-177.

Contandriopoulos, A.-P., Rey, L., Brousselle, A., \& Champagne, F. (2012). Évaluer une intervention complexe : Enjeux conceptuels, méthodologiques et opérationnels [Evaluating a complex intervention: 
Conceptual, methodological and operational issues]. The Canadian Journal of Program Evaluation, 26(3), 1-16.

Cooper, J. E. (2012). Reflections on the professionalization of occupational therapy: Time to put down the looking glass. Canadian Journal of Occupational Therapy, 79, 199-210. https://doi.org/10.2182/ cjot.2012.79.4.2

Craik, J., Davis, J., \& Polatajko, H. J. (2013). Introducing the Canadian Practice Process Framework (CPPF): Amplifying the context. In E. A. Townsend, \& H. J. Polatajko (Eds.), Enabling occupation II: Advancing an occupational therapy vision for health, well-being \& justice through occupation, 2nd ed. (pp. 229-246). Ottawa, ON: CAOT Publications ACE.

Davidoff, F. (2019). Understanding contexts: How explanatory theories can help. Implementation Science, 14(1), 23. https://doi.org/10.1186/ s13012-019-0872-8

Demers, L., \& Pelchat, Y. (2012/2013). Mésestimée et méconnue, la contribution des services de soutien à domicile au vieillir chez soi [Underrated and misunderstood, the contribution of homecare services to growing old at home]. Canadian Review of Social Policy, 68(69), 39-54.

Donabedian, A. (1980). The definition of quality and approaches to its assessment. Ann Arbor, MI: Health Administration Press.

Durocher, E., Rappolt, S., \& Gibson, B. E. (2013). Occupational justice: Future directions. Journal of Occupational Science, 21(4), 431-442. https://doi.org/10.1080/14427591.2013.775693

Freeman, A. R., McWilliam, C. L., MacKinnon, J. R., DeLuca, S., \& Rappolt, S. G. (2009). Health professionals' enactment of their accountability obligations: Doing the best they can. Social Science and Medicine, 69, 1063-1071. https://doi.org/10.1016/j.socscimed.2009.07.025

Gray, C. S., Berta, W., Deber, R. B., \& Lum, J. (2014). Home and community care sector accountability. Healthcare Policy, 10(SP), 56.

Hébert, M., Maheux, B., \& Potvin, L. (2002). Théories qui émergent du quotidien de la pratique communautaire de l'ergothérapie [Theories stemming from day-to-day practice of community occupational therapy]. Canadian Journal of Occupational Therapy, 69, 31-39. https://doi. org/10.1177/000841740206900103

Hébert, R. (2012). L'assurance autonomie : Une innovation essentielle pour répondre aux défis du vieillissement [Autonomy insurance: An essential innovation to meet the challenge of aging]. Canadian Journal on Aging, 31, 1-11. https://doi.org/10.1017/S0714980811000614

Lamarche, P., Pineault, R., \& Brunelle, Y. (2007).Modes d'organisation des services prometteurs pour le Québec. Rapport déposé au Groupe de travail sur le financement des services de santé [Promising ways to organize services in Québec. Report to the Financing Healthcare Services Working Group].

Lindsay, P. H., \& Norman, D. A. (1977). Human information processing: An introduction to psychology, 2nd ed. New York, NY: Academic Press.

Mackey, H. (2014). Living tensions: Reconstructing notions of professionalism in occupational therapy. Australian Occupational Therapy Journal, 61, 168-176. https://doi.org/10.1111/1440-1630.12097

McCoy, L. (2006). Keeping the institution in view: Working with interview accounts of everyday experience. In D. E. Smith (Ed.), Institutional ethnography as practice (pp. 109-125). Lanham, MD: Rowman \& Littlefield Publishers Inc.

Ministère de la santé et des services sociaux. (2017). Planification stratégique du ministère de la Santé et des Services sociaux du Québec. 2015-2020. Mise à jour 2017 [Strategic planning of the Québec Ministry of Health and Social Services. 2015-2020. Updated 2017]. Québec: Author.

Norman, G. R. (2005). Research in clinical reasoning: Past history and current trends. Medical Education, 39, 418-427. https://doi. org/10.1111/j.1365-2929.2005.02127.x

Oomkens, R., Hoogenboom, M., \& Knijn, T. (2016). Performance-based contracting in home-care work in the Netherlands: Professionalism under pressure? Health and Social Care in the Community, 24(4), 399410. https://doi.org/10.1111/hsc.12218

Pfadenhauer, L. M., Gerhardus, A., Mozygemba, K., Lysdahl, K. B., Booth, A., Hofmann, B., ... Rehfuess, E. (2017). Making sense of complexity in context and implementation: The Context and Implementation of Complex Interventions $(\mathrm{ClCl})$ framework. Implementation Science, 12(1), 21. https://doi.org/10.1186/s13012-017-0552-5

Poland, B., Lehoux, P., Holmes, D., \& Andrews, G. (2005). How place matters: Unpacking technology and power in health and social care. Health and Social Care in the Community, 13(2), 170-180. https://doi. org/10.1111/j.1365-2524.2005.00545.x

Polatajko, H. J., Backman, C., Baptiste, S., Davis, J., Eftekhar, P., Harvey, A., ... Connsor-Schisler, A. (2013). Human occupation in context. In E. A. Townsend, \& H. J. Polatajko (Eds.), Enabling occupation II: Advancing an occupational therapy vision for health, well-being \& justice through occupation, 2nd ed. (pp. 37-61). Ottawa, ON: CAOT Publications ACE.

Powell, A. E., Davies, H. T. O., Bannister, J., \& Macrae, W. A. (2009). Understanding the challenges of service change - Learning from acute pain services in the UK. Journal of the Royal Society of Medicine, 102, 62-68. https://doi.org/10.1258/jrsm.2008.080194

Rostgaard, T. (2012). Quality reforms in Danish home care - balancing between standardisation and individualisation. Health and Social Care in the Community, 20(3), 247-254. https://doi. org/10.1111/j.1365-2524.2012.01066.x

Rudge, T. (2013). Desiring productivity: Nary a wasted moment, never a missed step!. Nursing Philosophy, 14, 201-211. https://doi. org/10.1111/nup.12019

Schell, B. A. (2009). Professional reasoning in practice. In E. B. Crepeau, E. S. Cohn, \& B. A. Schell (Eds.), Spackman's occupational therapy, 11th ed. (pp. 314-327). Philadelphia, PA: Wolters Kluwer | Lippincott Williams \& Wilkins.

Schell, B. A. B., Unsworth, C. A., \& Schell, J. W. (2008). Theory and practice: New directions for research in professional reasoning. In B. A. B. Schell, \& J. W. Schell (Eds.), Clinical reasoning and professional reasoning in occupational therapy (pp. 401-431). Baltimore, MD: Lippincott Williams \& Wilkins.

Schell, J. W., \& Schell, B. A. B. (2008a). Teaching for expert practice. In B. A. B. Schell, \& J. W. Schell (Eds.), Clinical and professional reasoning in occupational therapy (pp. 258-288). Baltimore, MD: Lippincott Williams \& Wilkins

Schell, J. W., \& Schell, B. A. B. (2008b). Professional reasoning as the basis of practice. In B. A. B. Schell, \& J. W. Schell (Eds.), Clinical and professional reasoning in occupational therapy (pp. 3-12). Baltimore, MD: Lippincott Williams \& Wilkins.

Smith, D. E. (1987). The everyday world as problematic: A feminist sociology. Boston, MA: Northeastern University Press.

Smith, D. E. (2001). Texts and the ontology of organizations and institutions. Studies in Cultures, Organizations and Societies, 7, 159-198. https://doi.org/10.1080/10245280108523557

Smith, D. E. (2005). Institutional ethnography: A sociology for people. Lanham, MD: Rowman \& Littlefield Publishers Inc.

Smith, D. E. (2006). Incorporating texts into ethnographic practice. In D. E. Smith (Ed.), Institutional ethnography as practice (pp. 65-88). Lanham, MD: Rowman \& Littlefield Publishers Inc.

Smith, P. (2010). Measuring productivity in health services. Journal of Health Services Research and Policy, 15, 1-2. https://doi.org/10.1258/ jhsrp.2009.009141

Sturmberg, J. P., O'Halloran, D. M., \& Martin, C. M. (2012). Understanding health system reform - a complex adaptive systems perspective. Journal of Evaluation in Clinical Practice, 18, 202-208. https://doi. org/10.1111/j.1365-2753.2011.01792.x

Tousignant, M., Dubuc, N., Hébert, R., \& Coulombe, C. (2007). Homecare programmes for older adults with disabilities in Canada: How 
can we assess the adequacy of services provided compared with the needs of users? Health and Social Care in the Community, 15(1), 1-7.

Townsend, E. A., Polatajko, H. J., Craik, J. M., \& von Zweck, C. M. (2011). Introducing the Leadership in Enabling Occupation (LEO) model. Canadian Journal of Occupational Therapy, 78, 255-259. https://doi. org/10.2182/cjot.2011.78.4.7

Turner, S. M. (2006). Mapping institutions as work and texts. In D. E. Smith (Ed.), Institutional ethnography as practice (pp. 139-161). Lanham, MD: Rowman \& Littlefield Publishers Inc.

Vabø, M. (2012). Norwegian home care in transition-heading for accountability, off-loading responsibilities. Health and Social Care in the Community, 20(3), 283-291. https://doi. org/10.1111/j.1365-2524.2012.01058.x
WHO. (2010). Health systems financing: The path to universal coverage. Geneva, SW: Author.

How to cite this article: Carrier A, Freeman A, Desrosiers J, Levasseur M. Institutional context: What elements shape how community occupational therapists think about their clients' care?. Health Soc Care Community. 2020;28:12091219. https://doi.org/10.1111/hsc.12954 